\title{
An inclusive,
}

innovative

and secure

Nordic region

THE SWEDISH

PRESIDENCY 2018

(1I) Nordic Council of Ministers

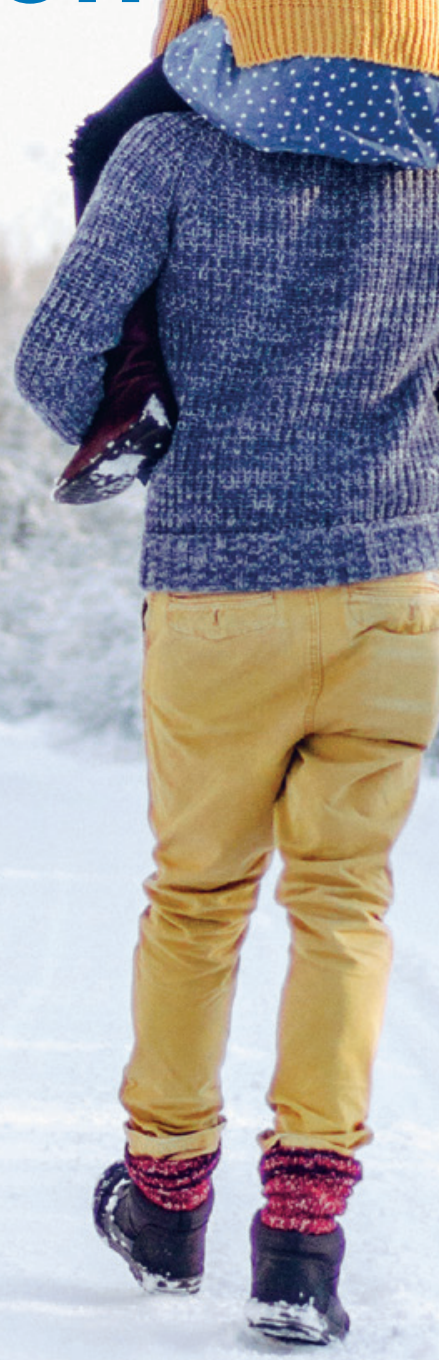




\title{
An inclusive, innovative and secure Nordic region THE SWEDISH PRESIDENCY 2018
}

\author{
ANP 2017:755 \\ ISBN 978-92-893-5132-4 (PRINT) \\ ISBN 978-92-893-5133-1 (PDF) \\ ISBN 978-92-893-5134-8 (EPUB) \\ http://dx.doi.org/10.6027/ANP2017-755 \\ (C) Nordic Council of Ministers 2017 \\ Layout: Louise Jeppesen \\ Photo: Momenti.lv \\ Print: Rosendahls \\ Copies: 1,200 \\ Printed in Denmark

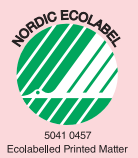

\section{Nordic co-operation}

Nordic co-operation is one of the world's most extensive forms of regional collaboration, involving Denmark, Finland, Iceland, Norway, Sweden, the Faroe Islands, Greenland, and Åland.

Nordic co-operation has firm traditions in politics, the economy, and culture. It plays an important role in European and international collaboration, and aims at creating a strong Nordic community in a strong Europe.

Nordic co-operation seeks to safeguard Nordic and regional interests and principles in the global community. Shared Nordic values help the region solidify its position as one of the world's most innovative and competitive.

\section{Nordic Council of Ministers \\ Nordens Hus \\ Ved Stranden 18 \\ DK-1061 Copenhagen K \\ www.norden.org}

Download Nordic publications at www.norden.org/nordpub 


\section{Programme for \\ the Swedish Presidency of the Nordic Council of Ministers}

Contents

4 Greetings from the Prime Minister and the Minister for Nordic co-operation

6 An inclusive Nordic region

12 A sustainable and innovative Nordic region

18 A secure and open Nordic region

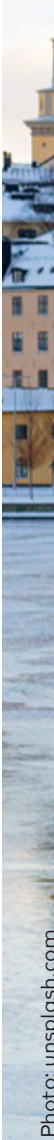




\section{Greetings from the Prime Minister and the Minister for Nordic co-operation}

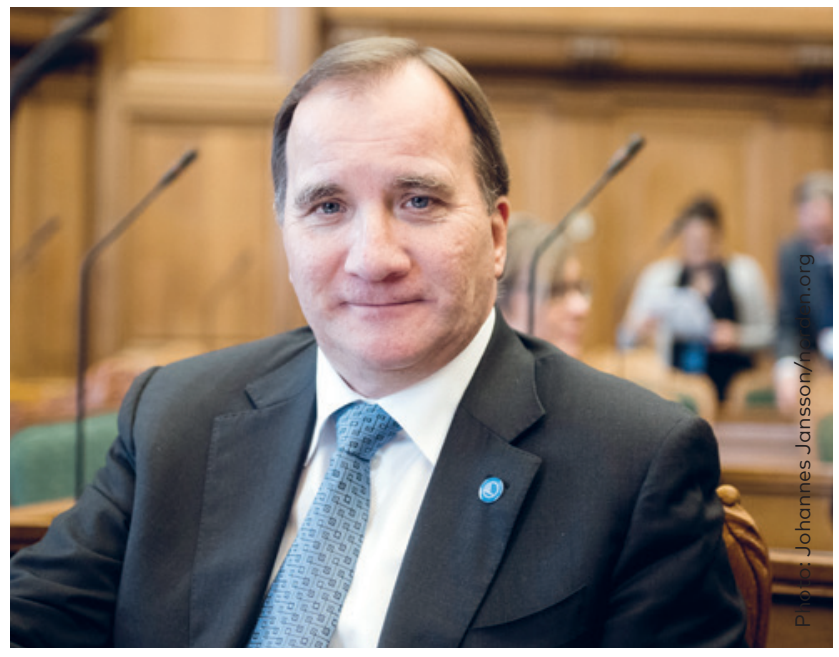

Prime Minister

Stefan Löfven

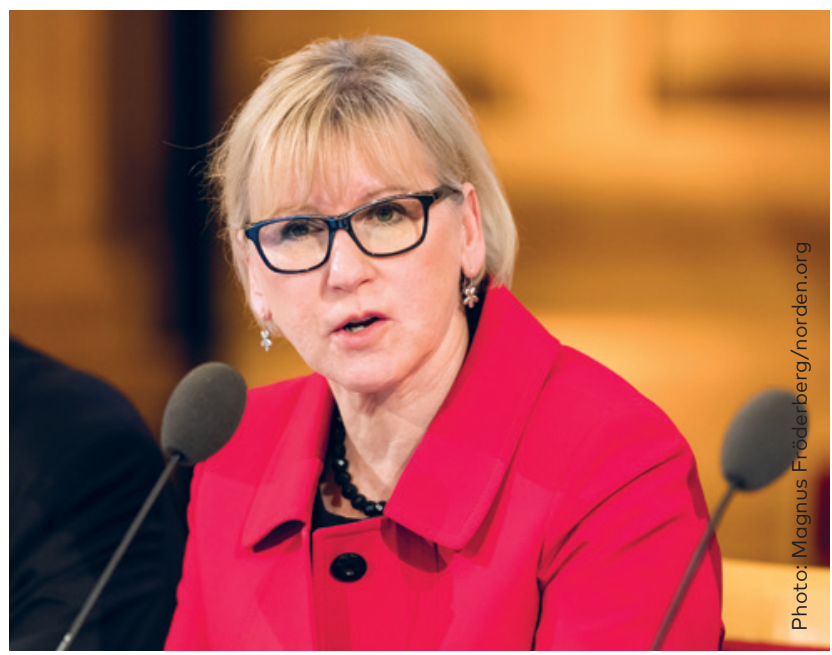

Minister for Foreign Affairs and Nordic co-operation Margot Wallström 
The Nordic countries have a strong democratic and civil society tradition. Equality, sustainability and co-operation are our common foundation. In a global comparison, we have a high level of trust in our public institutions and our rulesbased societies. This trust has developed over a long period of time and is the glue that holds the Nordic model together. In an increasingly uncertain world this trust must be constantly protected and re-earned.

The Nordic countries are leaders in promoting gender equality. Sweden has a feminist government. The gender equality perspective is a cornerstone of our national and international policies.

Nordic co-operation takes place in everyday life, often unglamorously, in a continuous exchange of information, knowledge and culture. The organic nature of our co-operation lies at the root of the Nordic prime ministers' vision of the Nordic region as the world's most integrated region.

We in the Nordic countries know from experience that open, sustainable and gender-equal societies lead to prosperity. This is why we must protect European cohesion and be active within the UN, the hub of the rules-based international order.

In an increasingly uncertain international context, the Nordic countries stand by their promise to future generations as enshrined in the Paris Agreement and the 2030 Agenda. Globalisation requires efforts to strengthen equality so that the gaps do not grow between those who benefit from globalisation and those who risk losing out.

Through the prime ministers' initiative Nordic Solutions to Global Challenges - we hope to spread our experiences to other countries while also increasing our efforts at home.

An inclusive, sustainable, innovative, secure and open Nordic region is the starting point when Sweden assumes the Presidency of the Nordic Council of Ministers in 2018. Digitalisation is a recurrent theme.

In 2018, four projects will be launched linked to our presidency programme in areas where we see a clear added value of stepping up Nordic co-operation and exchange of experiences. These involve solutions for remote health care and ePrescriptions across borders, measures to promote young people's social inclusion and democratic participation, climate-smart mobility in cities, and wooden construction and sustainable design.

In 2018, Sweden will also chair the Council of the Baltic Sea States, the Barents Euro-Arctic Council and coordinate the informal Nordic and NordicBaltic foreign and security policy cooperation. Our ambition is to find points of contact between these formats and all countries in the Baltic Sea region so as to strengthen overall regional co-operation. 


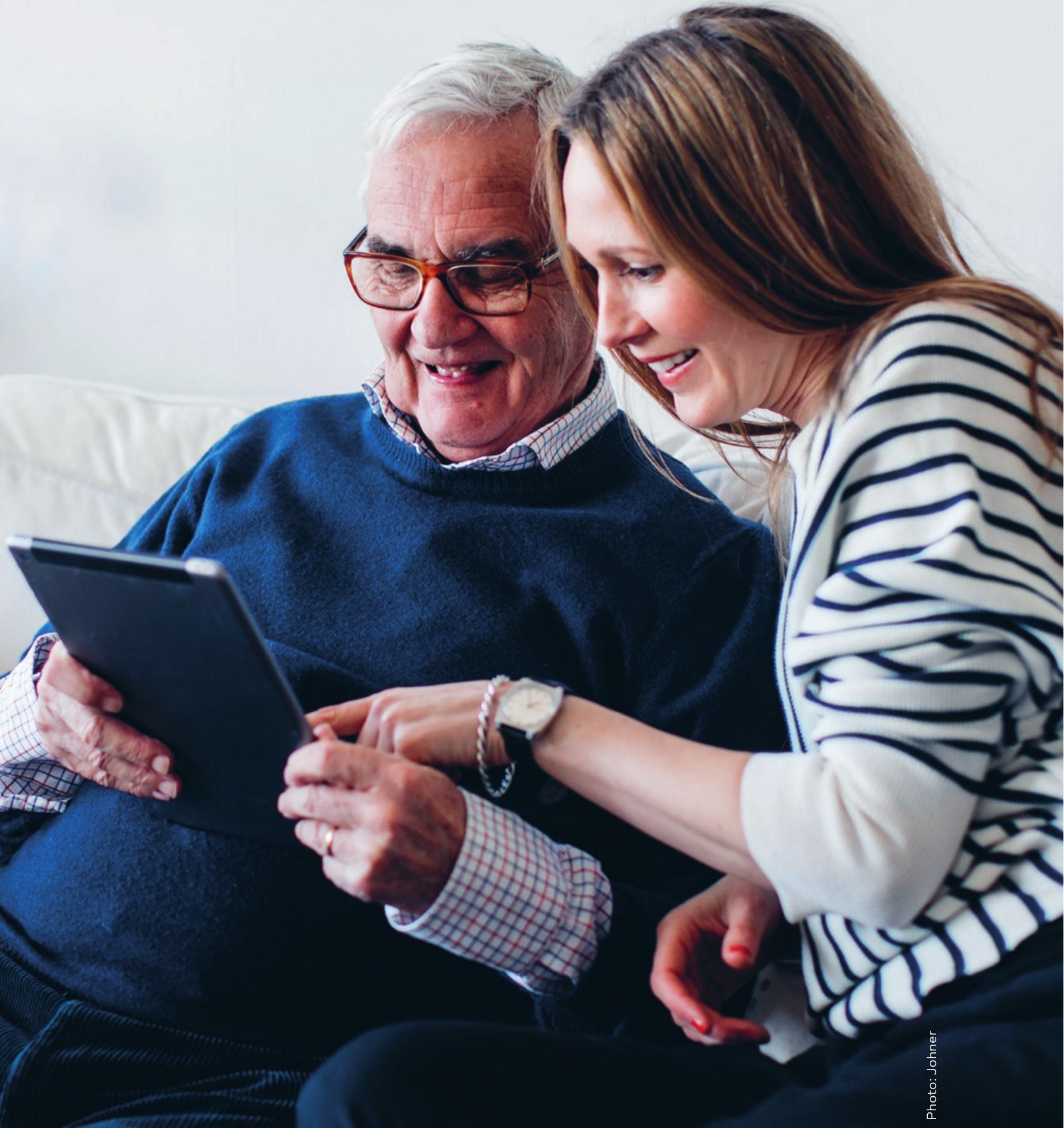


An inclusive Nordic region

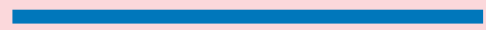


Labour participation and close cooperation between the social partners are two characteristics of the Nordic labour market. The Nordic countries have shown that general welfare policies promote both individual liberation and economic growth. In light of a growing and ageing Nordic population, it is crucial for sustainable Nordic welfare that more people find employment and that there are opportunities to remain in the work force longer.

It must be possible to live, work and run a business in both rural and urban areas. This requires reliable access to transport and services, as well as proximity to education and innovation environments. Digital long-distance solutions can contribute to vibrant rural areas in the Nordic countries. This applies, not least, to the border regions where access to resources in the neighbouring country may improve security and increase mobility.

The barriers and the lack of information that in various ways make it more difficult to move, commute, study or run a business across borders in the Nordic region must be reduced. During 2018 , Sweden will actively work towards this in the Freedom of Movement Council. At the same time, Nordic authorities are urged to consider solutions in all areas that promote a more integrated Nordic region.

Cross-border eAdministration and better coordination of nationally developed digital solutions increase freedom of movement for people, goods, services and data. Implementation of the declaration adopted by the digitalisation ministers of the Nordic and Baltic countries at the Digital North conference in April 2017 is a priority. In 2018, Sweden will host a Nordic digitalisation ministers meeting and follow-up the Digital North declaration with a ministerial conference where politicians and industry representatives from the Nordic and Baltic countries will discuss how to push the digital agenda forward.

Digital solutions can contribute to more equitable and gender-equal health and social care. The first of Sweden's four 
presidency projects will support the development of solutions for remote health care and ePrescriptions across Nordic borders. One goal of the project is to have the technical requirements in place within three years to exchange ePrescriptions in the Nordic region.

Collaboration on health, medical and social care provides better access to export markets. The joint project initiated by the Nordic prime ministers Nordic Welfare Solutions - will continue.

Fair conditions in the labour market require measures within several policy areas, as well as collaboration between the social partners. The Nordic countries can learn from each other, and they can also offer valuable experience to countries outside the region. Companies that break the rules in pursuit of short-term gains create unfair competition in the labour market. This issue will be a priority during the Swedish Presidency.

Technological developments and globalisation will result in new jobs emerging and others disappearing. New skills will be in demand. This will require political foresight and adaptability.

In 2018, Sweden will host a conference on the future of the labour market. Particular focus will be on the consequences of digitalisation, robotisation and automation, and the kind of knowledge this will require. The material and reports produced within the framework of the conference will form part of the Nordic contribution to the 100th anniversary of the International Labour Organisation in 2019.

Women in the Nordic countries have a high level of labour force participation. However, the employment rate for women is still considerably lower than for men, especially for women born abroad. A Nordic conference targeting these issues will be held in spring 2018.

Another project of the Nordic prime ministers' initiative - Nordic Gender Effect at Work - puts the spotlight on the global challenges to achieving gender equality and creating decent working conditions for all. In 2018, Sweden will 
host an international conference on men and gender equality on the theme of masculinity. In connection with the conference, a meeting between the Nordic and Baltic ministers for gender equality will be held.

Unequal labour force participation contributes to the wage gap, which in turn leads to differences in pensions between women and men. Sweden will initiate a Nordic study that can provide the basis for continued efforts to achieving gender-equal pensions.
The Nordic countries are facing similar challenges concerning the social inclusion of young people. Sweden's second presidency project aims to promote young people's democratic participation by sharing best practices at the Nordic level. The project will take place in close co-operation with civil society organisations, with the long-term objective to help combat segregation.

Several digital tools for language learning and communication have been developed in recent years to facilitate integra-
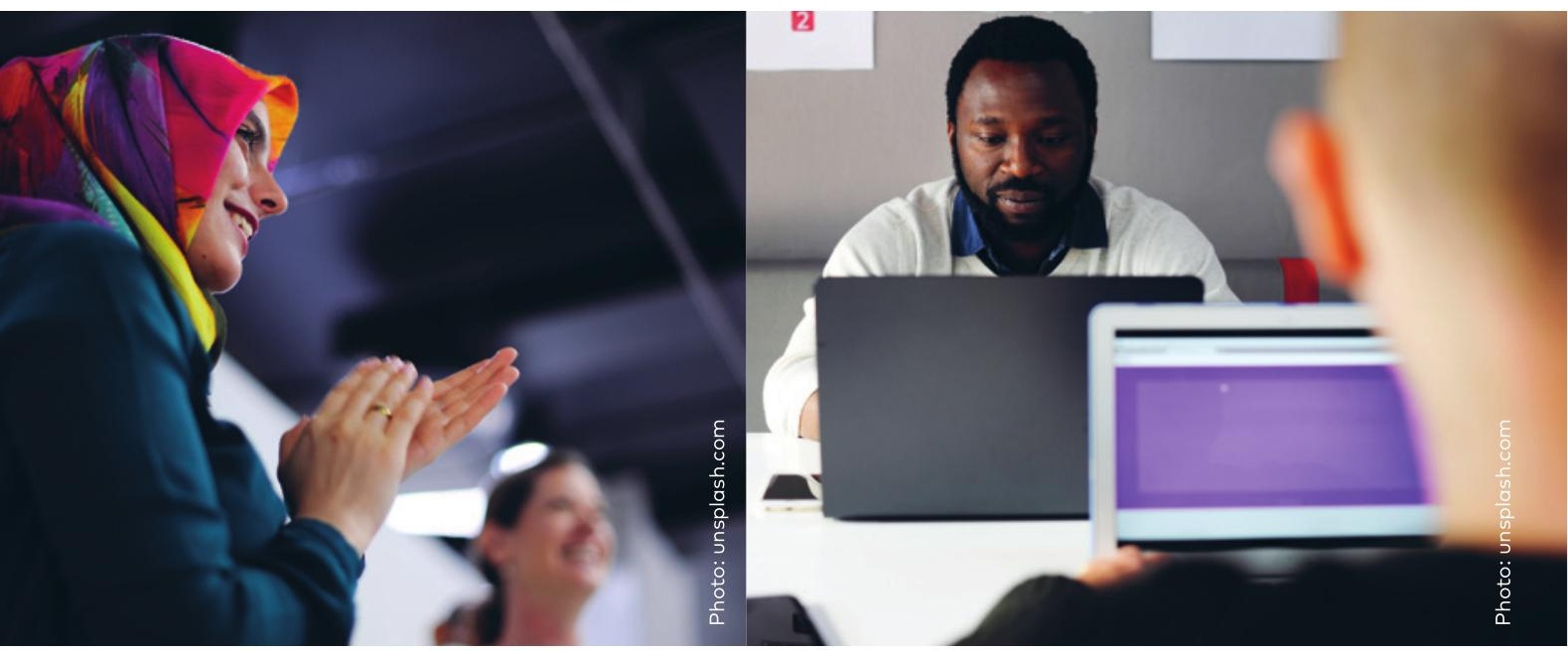
tion. Experience exchange between the Nordic countries will be intensified in this area, within the framework of the Nordic co-operation programme on integration.

During its Presidency, Sweden will follow up the report on enhanced and renewed Nordic education co-operation.

The results of the strategic review of Nordic co-operation in the area of social policy will be presented next year.
The Swedish Presidency also wants to encourage a dialogue on which Nordic institutions and projects our Baltic neighbours may be interested in joining.

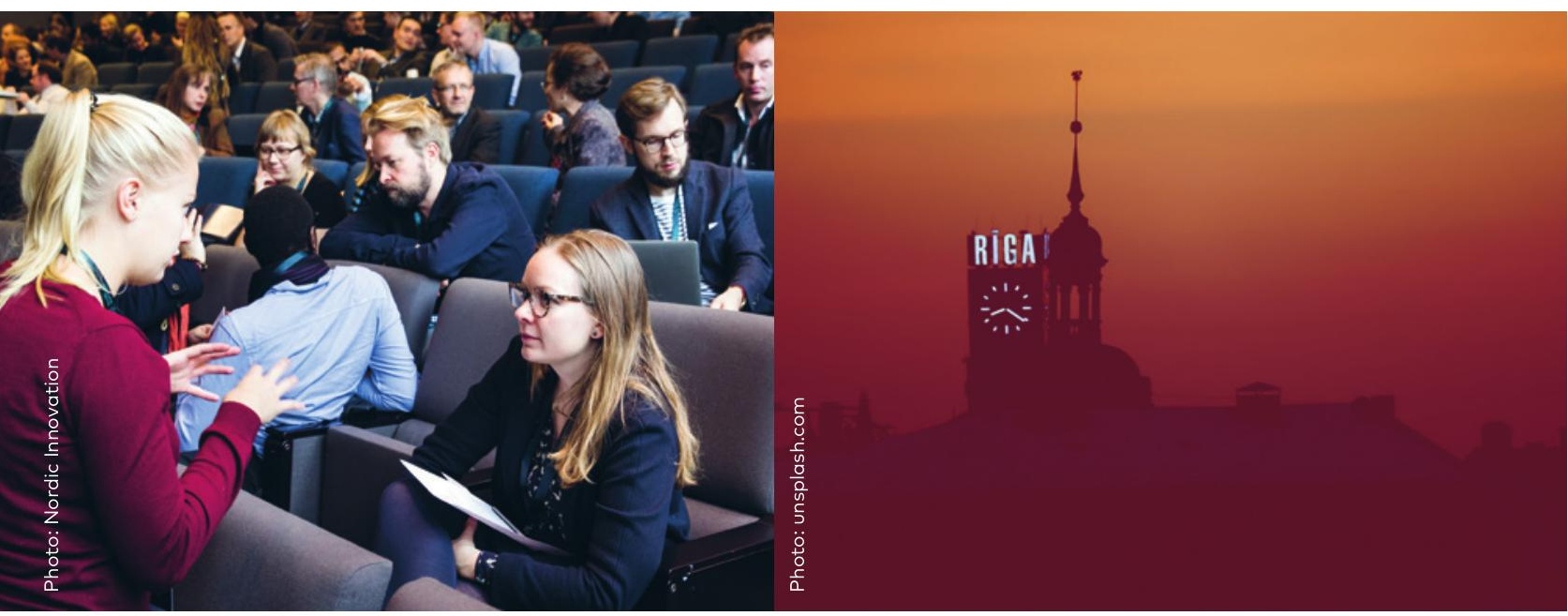




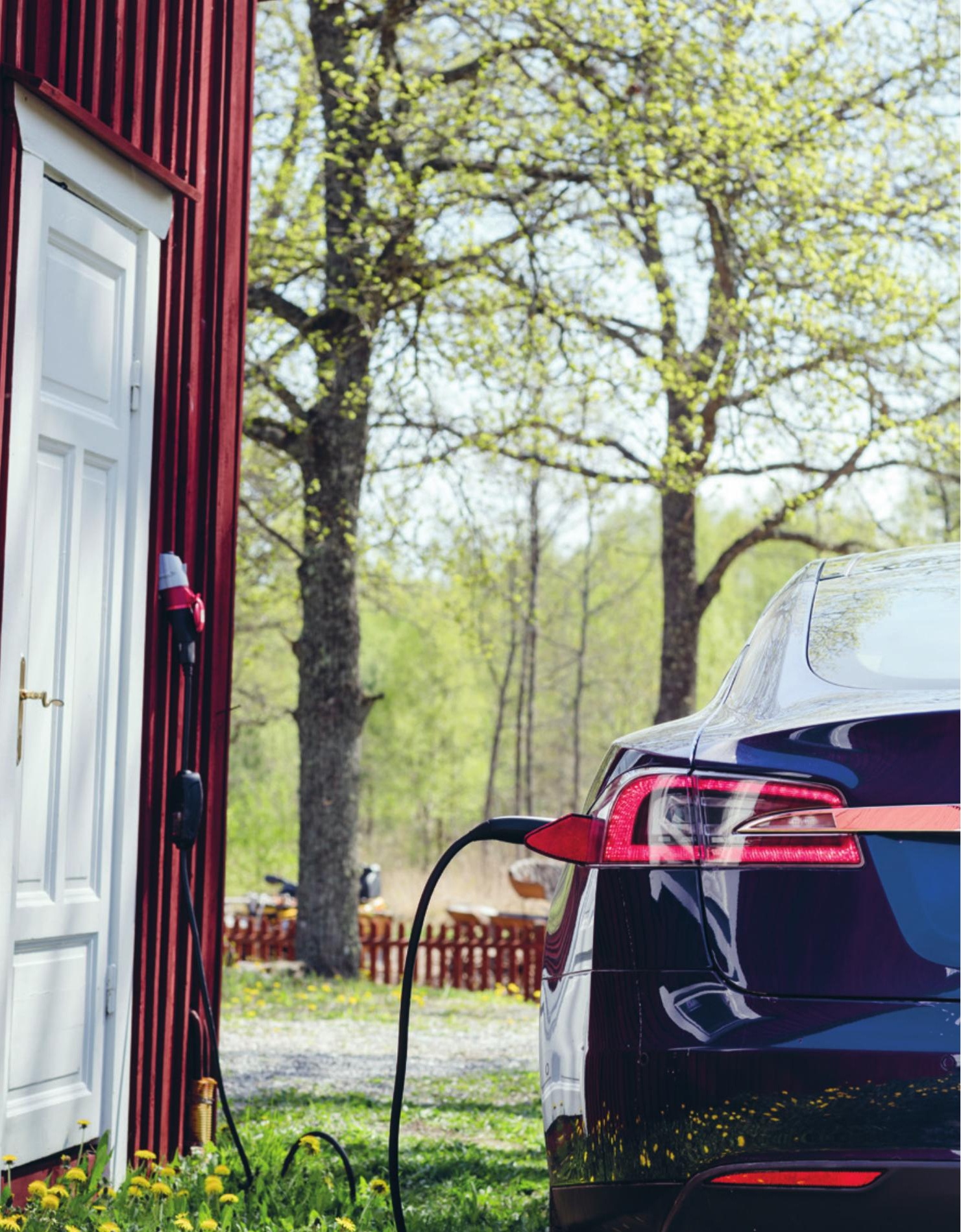

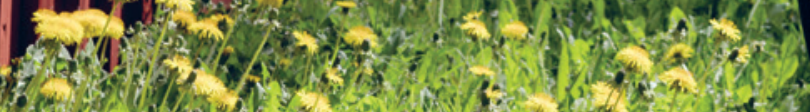

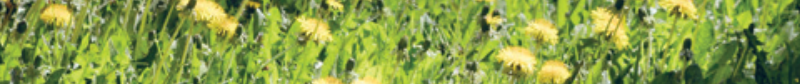

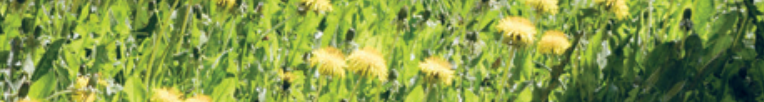


A sustainable and innovative Nordic region 
The Nordic region has a tradition of strong commitment to environmental issues. It was in Sweden that the first UN conference on the environment was held in 1972, and it was a Norwegian prime minister who, in 1987, introduced the term 'sustainable development' to world politics.

The Nordic countries have been able to reduce their overall impact on the environment and the climate, while the region's growth has remained at the same level, or higher, than the OECD average. Climate change is one of the greatest challenges to humanity, and far-reaching measures are needed if we are to hand over a sustainable world to future generations.

The state of the oceans is alarming. Plastic in the oceans is causing considerable problems and this is why the Nordic environment ministers adopted a joint plastic programme in 2017. This initiative will help to reduce the negative impact plastic has on the environment.

The UN Ocean Conference demonstrated strong global commitment and highlighted in particular the link between oceans and the climate. During its Presidency, Sweden intends to host a Nordic ministerial discussion on how to follow up the UN Ocean Conference.

The strategic review of Nordic climate and environmental co-operation will be presented in spring 2018 and form the basis of the new four-year co-operation programme which will then be adopted. A high-level meeting is planned to support Nordic implementation of the Paris Agreement.

In 2018, Sweden intends to launch an inquiry into how the Nordic environmental and climate finance architecture can be optimised. The purpose is to map out current financing gaps and produce concrete proposals for how the three Nordic institutions - the Nordic Investment Bank (NIB), the Nordic Environment Finance Corporation (NEFCO) and the Nordic Development Fund (NDF) - as well as state development financiers, can help to plug those gaps, taking the institutions' different mandates and governance systems into consideration. 
The Nordic Council of Ministers'

Arctic Co-operation Programme will be renewed during Sweden's Presidency. The focus will be on enhanced collaboration on the implementation of the climate goals and the 2030 Agenda.

The Nordic Ecolabel has drawn up criteria for giving investment funds the right to use the Nordic Swan Ecolabel. The ecolabel makes it easier for consumers to choose funds with a sustainability focus. It also helps to increase focus on sustainability, among both fund managers and the companies to be invested in.

All Nordic countries need to adapt their transport sectors to become fossil-free. Co-operation is necessary to facilitate sustainable cross-border transportation between our countries. The third Swedish presidency project will promote climate-smart mobility in Nordic cities. The aim is to contribute to sustainable urban development by supporting the transition to fossil-free transport in Nordic cities and urban regions.

Nordic Climate Solutions - one of the projects within the Nordic prime minis- ters' initiative - seeks to reduce global $\mathrm{CO} 2$ emissions by encouraging the phasing out of fossil fuel subsidies combined with an increased spread of existing Nordic climate solutions to other parts of the world.

The Nordic countries, with their sound expertise and rich natural resources, have good prospects of leading the development towards a bio-based economy. Co-operation with the Baltic countries in this area seems to be a natural choice. Sweden is building on the Icelandic Presidency's initiative from 2014 to further enhance Nordic co-operation on bio-economy.

A forestry industry that is environmentally and economically sustainable is positive for the climate, vibrant rural areas and a growing circular and biobased economy. The Nordic roadmap - Nordic Forest Solutions - is advancing forestry co-operation.

Nordic co-operation is needed to gain support in the EU and other international forums for the notion that sustainable forestry is compatible with 
biodiversity, recreation and the good use of forest-based materials.

Increased urbanisation in the Nordic countries means a growing need for housing, particularly in the metropolitan regions. Creating better conditions for construction, with fewer cross-border barriers and increased competitiveness in the Nordic construction sector, will be a priority during the Swedish Presidency. A meeting between the ministers responsible for building and housing will be held in May 2018.

The Nordic region is rich in renewable resources but enhanced co-operation is needed to spread Nordic solutions. Increased building in wood is energyefficient and contributes to the longterm storage of $\mathrm{CO} 2$, while also promoting a market for sustainable construction within and beyond the Nordic region. Industrial wood construction, combined with a platform for architecture and design that promote sustainability, in line with the 2030 Agenda, is the fourth project of the Swedish Presidency.
Nordic design and architectural solutions have internationally renowned potential. A Nordic architecture conference will be arranged.

There is a great deal of interest in Nordic art and culture around the world. The 'Nordic Spring' cultural festival will take place in Montreal in 2018. Strong Nordic cultural co-operation, at political and individual level, will be highlighted during the Nordic cultural summit in Malmö in May 2018, in connection with the Nordic culture ministers meeting.

Co-operation on international branding of the Nordic region will receive particular attention during the Swedish Presidency.

The Nordic electricity market is one of the most advanced in the world. Through innovative co-operation it can be developed further, giving citizens and companies better opportunities in an efficient end-user market.

Another project under the Nordic prime ministers' initiative - Nordic Energy 
Solutions - aims to improve access to renewable energy in other regions of the world, which in turn could increase the export opportunities for Nordic companies. The possibilities of marketing Nordic energy solutions will be particularly good when the Nordic countries jointly host the Clean Energy Ministerial (CEM) and Mission Innovation (MI) meetings in the Öresund region in May 2018.

One important objective of Nordic efforts in this field is to influence the EU's energy union. During the Swedish Presidency, a new Nordic energy policy co-operation programme will be launched, focusing on more efficient energy use and a faster transition to renewable energy sources.

The Nordic Council of Ministers played an important role in establishing Nordic Mobile Telephone (NMT) and GSM (2G) as new world standards. Once again, the Nordic region has the opportunity to take a leading position when the next generation technology for mobile data transfer - 5G - is on the verge of a breakthrough.
In order to promote dialogue between politicians and the business sector, industry representatives will be invited to present how $5 \mathrm{G}$ can contribute in the areas of elderly care and eHealth, as well as to innovative transport solutions and climate-smart cities.

In the area of business and innovation, Sweden will focus on the opportunities offered by digitalisation for small and medium-sized enterprises. This includes test beds, automation and digitalised business models, as well as how the public sector can be a driving force in innovation procurement. The new Nordic Co-operation Programme for Innovation and Business Policy 2018-2021 will be launched during the Swedish Presidency.

Research is a priority in Nordic co-operation. The majority of the Nordic Council of Ministers' research investments are channelled through the Nordic institution NordForsk. Sweden will emphasise the continued need for a clear added value in the activities of NordForsk in relation to ongoing research at national and European level. 

120 (2)

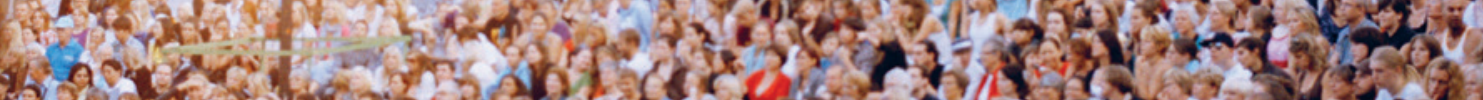
9. 45 ser

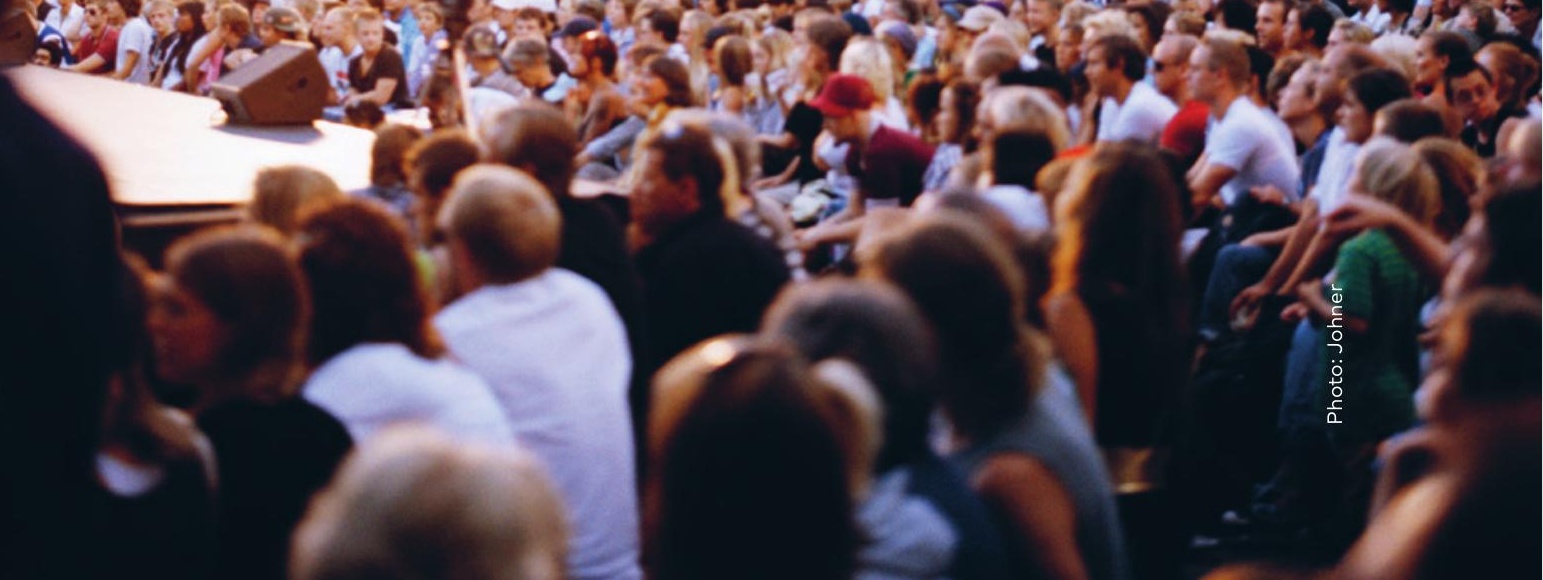


A secure

and open

Nordic region

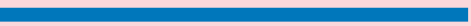


Several Nordic countries are now drafting, or have already produced, national security strategies. The Swedish Presidency will give priority to greater coordination and an intensified exchange of experience within our region on broad security issues.

During 2018, Sweden will also lead Nordic co-operation on contingency planning, which is based on the 'Haga Declaration'. The current development goals apply for the period 2015-2018 and will therefore be renewed during Sweden's Presidency.

Improved interoperability between the Nordic countries' operations personnel and resources for civil security will be sought. In 2016, Sweden and Norway became the first countries in the world to link their national radio communications systems, Rakel and Nødnett. Work is under way in both Norway and Sweden to connect these to Finland's corresponding system, Virve. There is a preparedness to establish similar co-operation with Denmark.
The repeated terrorist attacks in Europe, which have also affected the Nordic countries, warrant increased co-operation. Targeted action is necessary to prevent radicalisation and support individuals wishing to leave violent extremist environments. Co-operation between the Nordic countries is already taking place, primarily via the Nordic network for preventing extremism at national level, and via Nordic Safe Cities at local level.

In 2018, experience exchange will continue between the Nordic countries on how the challenges of organised crime and terrorism can best be addressed.

A new Nordic co-operation programme for the justice sector is being drawn up.

Sweden will build on the work begun during the Finnish and Norwegian presidencies to support teachers in dealing with controversial issues in their teaching. Additional measures, such as developing a digital education module and organising additional training sessions for teachers, will be reviewed. 
The media landscape is currently undergoing major changes, with the shift towards digitalisation and new actors emerging. Alternative sources of information are playing an increasingly important role in shaping opinion. This development underlines the importance of high-quality news media and places greater demands on source criticism. Empowering children and young people as conscious media users, while also protecting them from harmful media influences, will be a priority during Sweden's Presidency.
At a time when news providers are increasingly anonymous, issues concerning freedom of expression are becoming more relevant. Deliberate disinformation and state-controlled propaganda activities online are becoming more common and undermining trust in institutions and traditional media actors. The discussion about the role of traditional news media and public service will be intensified. The Nordic Council of Ministers' support to independent Russian-language media in the Baltic countries will continue.

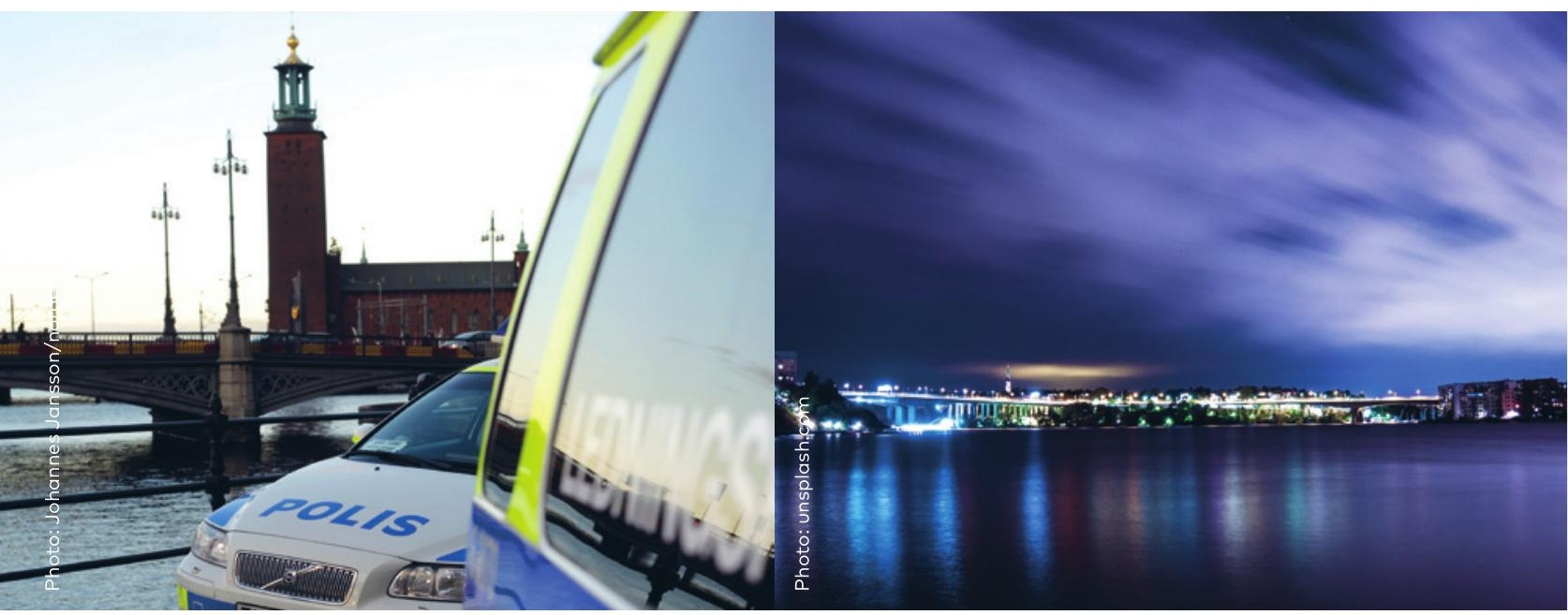


The climate of discussion and debate in the Nordic countries has hardened, which can be seen in threats and hatred targeting elected representatives, journalists and artists. The safe haven system in the Nordic countries will receive particular attention.

As increasing numbers of people are forced to leave their home countries, there is a heightened risk of various forms of exploitation and human trafficking. Integration and labour market participation are important building blocks for reducing vulnerability and engaging migrants in the host country. Sweden will seek to strengthen co-operation in the Nordic region and with the countries around the Baltic Sea to combat human trafficking.

Safety and security have several dimensions. Sustainable development of the Nordic food systems, with a focus on efficient and responsible production and consumption, is fundamental for our food security. The potential of food cul- ture in the Nordic region is made visible through the 'New Nordic Food' initiative. On the basis of the manifesto for new Nordic cuisine, food development that takes account of the environment, animal ethics, business aspects and gastronomy will be promoted.

Nordic co-operation on sustainable preservation and the use of our common plant genetic resources through NordGen is internationally renowned. This co-operation needs to be continuously developed, not least in the digital area.

The Nordic countries have lower levels of antibiotic use than many other countries and therefore a better resistance status. Co-operation has been established between the human, animal, food and environmental sectors to maintain and develop this good resistance status. In 2018, Sweden intends to host meetings in both the strategy and the expert group on antimicrobial resistance. 

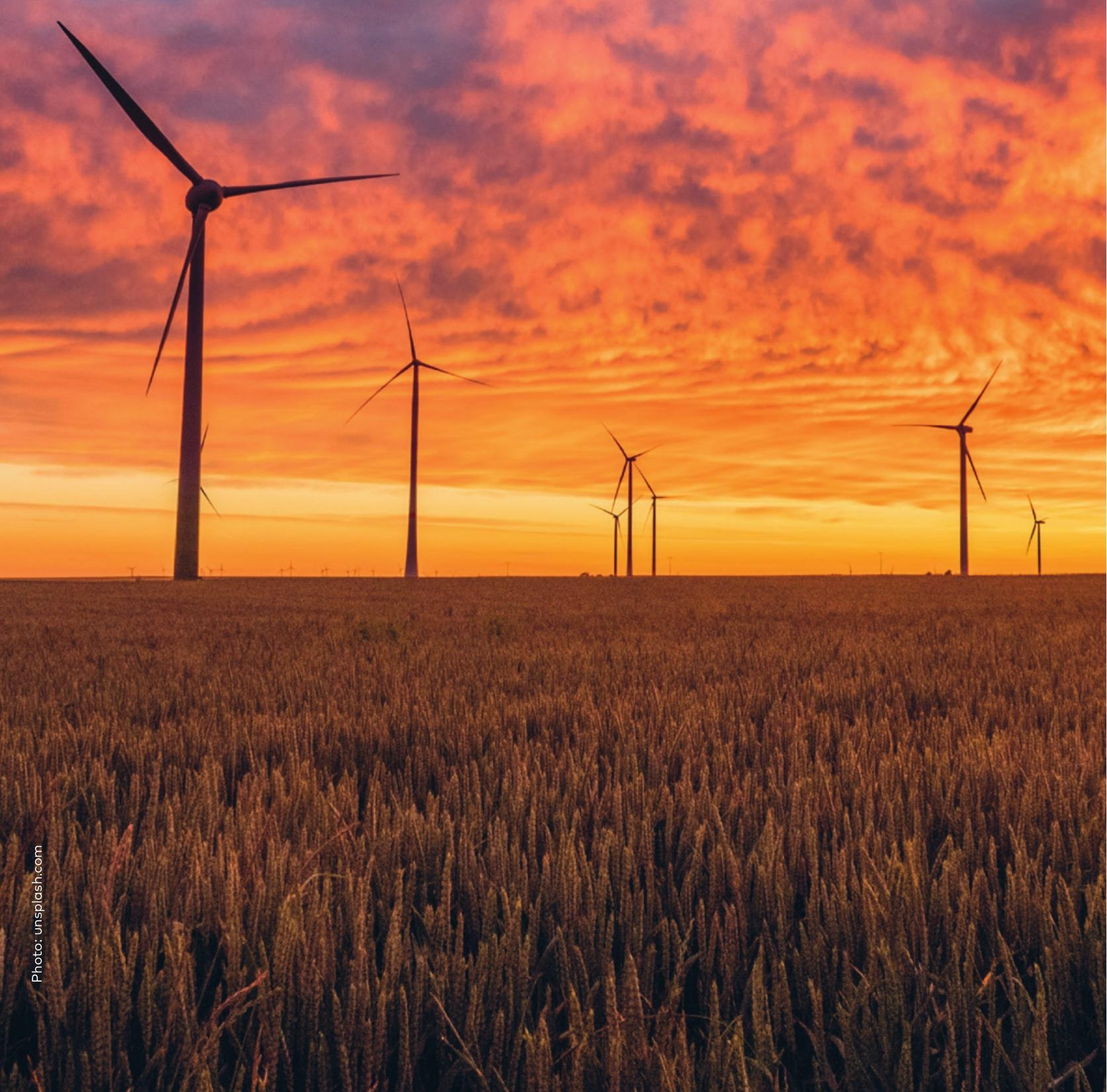
Nordic Council of Ministers

Nordens Hus

Ved Stranden 18

DK-1061 Copenhagen K

www.norden.org

\section{THE SWEDISH PRESIDENCY 2018}

An inclusive, sustainable, innovative, secure and open Nordic

region is the starting point when Sweden takes over the Presidency of the Nordic Council of Ministers in 2018. Digitalisation is a recurrent theme throughout Sweden's presidency programme.

The Nordic countries have a strong democratic and civil society tradition characterised by equity, gender equality, sustainability and co-operation. The continuous exchange of knowledge and culture provides the basis for the Nordic prime ministers' vision of the Nordic region as the world's most integrated region.

The Nordic countries have a strong international engagement and value European cohesion and an active UN. The Nordic prime ministers' initiative - Nordic Solutions to Global Challenges - aims to spread positive Nordic experience to the rest of the world. 